\title{
Partnerships: Creating Vocational Options for People with Mental Illness
}

When we were asked to consider co-editing a special issue for WORK focused on enabling employment of people who experience mental ill-health, the idea of partnership came to mind. Partnership has previously featured in a special issue by Shaw and Lindsay [1]; its focus was on the importance of collaboration with in the return-to-work process, featuring a key partnership with the Injured Workers Alliance of Canada. Notwithstanding the importance of these partnerships, this issue aims to examine a broad spectrum of employment related issues for individuals who experience mental illness, including return-to-work following acute mental illness; entering the workforce for the first time; and pathways to enhance vocational options. A significant feature of this issue is its consideration of the wideranging partnerships that have been fostered to assist with successful employment outcomes. We also sought to bring together international perspectives of these issues, with authors from Australia, Canada, England and Italy represented.

The need for collaborative partnerships in mental health practices is not new. Partnership has been recognized as an important aspect of clinical practice, research and implementation strategies [2]. As mental health services become further integrated within communities, partnerships with relevant community sectors will become a critical feature of implementing recovery-oriented care; especially, those related to the social determinants of health which often situate outside of the jurisdiction of health [3]. Recognition of the wealth of resources available in the community that are not formally (or financially) tied to government will be an important cornerstone of partnerships into the future. Partnerships beyond the health sector, for example, can provide important avenues for enabling vocational opportunities in education and employment. This special issue includes papers that raise education as an impor- tant, yet often neglected component of enhancing employment options [4], and present first-person accounts of return to education and employment $[5,6]$. Partnerships for diverse contexts are illuminated, including in supporting return-to-work [7]; in social firm development to increase employment options and sustainability [8-10]; in bridging the effects of geography, distance and limited human resources to provide employment services and supports [11]; in enabling volunteering as a pathway toward employment [12]; and in research with people experiencing mental illness and within the organizational context of work [13,14].

Krupa and Carter [4] raise the importance of education to improve employment options for people who experience mental illness. They describe a unique partnership between Queen's University and the Frontenac School Board in Kingston, Ontario, which has cultivated a supported employment program that fosters both degree completion and career development. Krupa and Carter further identify the importance of partnership to bridge the various sectors involved in facilitating the employment of persons with mental illness in Canada. Ben's story [5] then provides a thoughtful reflection from personal experience with an Australian supported education program and of its importance in the process of recovery. A university student when he became unwell, Ben describes a variety of partnerships forged within a self-directed education program for people experiencing mental illness. As Rinaudo and Ennals put it, "in a quantitative analysis of supported education, where outcomes are measured by course completion and employment, Ben would simply be a positive statistic. Sharing his story in this case study format brings that positive statistic to life and highlights the significance of education and employment in his experience of recovery." 
Cassinello and Bramley [6] provide a window into a unique employment program in the United Kingdom called USES - an acronym for User Support and Employment Service. This program is described though the narrative of Keeley's journey; Keeley being the first author. Keeley's journey illustrates the application of the locally developed WORKS framework in conceptualising and supporting Keeley's vocational recovery from being a service user to becoming a service provider. In particular, this narrative depicts the partnership between Keeley and an occupational therapist as they collaboratively developed a successful employment pathway.

Continuing the theme of successful return-to-work, Hatchard, Henderson and Stanton [7] give consideration to the salience of partnerships to support selfdirected return-to-work following an episode of acute mental illness. Hatchard and colleagues highlight the importance of self-management strategies, especially in partnership with the employer; and they identify how personal and workplace partnerships are integral to supporting workers as they take ownership of their full potential and self-direct return to mainstream employment. Three papers from Italy and Australia then discuss social firm development through partnerships between the business and non-profit sectors as a means to address the need for employment opportunity, and to create meaningful and lasting employment [8-10]. Villotti, Corbière et al. [8] examined the individual and environment variables that contributed to job satisfaction for persons with severe mental illness working in an Italian Social Firm. These authors found that workplace accommodation and social support, combined with higher occupational self-efficacy, significantly contributed to job satisfaction. While job satisfaction, and job accommodations are known to contribute to longer job tenure for people with severe mental illness $[15,16]$, job satisfaction in social firms had previously received little attention in the literature. Villotti et al. found that the more accepted and supported people felt by their work environment, the more satisfied they were with their jobs and determined to remain in them. Two studies in Australian social firms also explore the issues of how such workplaces support work success and sustained job tenure. An ethnographic study by Paluch et al. [9] highlights the complexity of running a socially-invested business, and the importance of cross-sectoral partnerships to support their operational success. Through exploration of the views of employees with mental illness working in a social firm established through a partnership with a disability employment support agency, Williams et al. [10] shed light on the features of workplaces that can be supportive in sustaining employment. Collectively, these papers give important consideration to retention and tenure, outcomes for which limited impact has been demonstrated in studies of evidence based supported employment [17].

Identifying geography, distance and limited human resources as further challenges to offering evidence based supported employment, Rebeiro Gruhl [11] presents findings from a qualitative case study of access to employment for persons with serious mental illness. This work draws upon a larger study that considered the influence of place on employment access in rural and northern Ontario. Rebeiro Gruhl argues that partnerships are an important aspect of bridging the effects of geography, distance and limited human resources in such locations, identifying how partnership may provide a mechanism for rural and other resource-limited communities to provide evidence-based supported employment. Focusing on enabling volunteering experiences, Fegan and Cook [12] provide a further perspective of partnership development between mental health services and service users, in which volunteering opportunities for those choosing this pathway toward employment have been created.

Together, the next set of papers highlight that learning more about how to support people with mental illnesses in their work environments is an important research platform for academia and government. The papers by Bryant et al. [13] and Moll [14] directly address this realm of research. Bryant et al. report on the experiences of an established collaborative research group involving mental health service users, which in one sense creates a context within which members use their experience and skills to make a valued contribution. Bryant et al. also underscore the importance of furthering our understanding of the need to create the time and space to fully engage people experiencing mental illness in the research process when researching topics that directly concern them. Moll takes a different focus, reflecting on the importance of collaboration and partnerships in research focused on employment issues and practices within organizations. Each paper highlights how partnerships are important to fully engaging critical parties in research, as well as to navigating the complexities and political sensitivities with which the researcher is presented whilst conducting organizational case study research.

This special issue is likewise the result of a partnership. We would like to thank each of the contributors 
for making this issue of WORK: A Journal of Prevention, Assessment and Rehabilitation possible. Special thanks are extended to Karen Jacobs, Editor, for the opportunity to share these perspectives on partnerships, and for sharing our belief in the importance of partnerships to enable people with mental illness to secure sustainable employment, retain preferred employment, and to build careers of their choosing.

\section{Guest Editors}

Karen Rebeiro Gruhl Health Sciences North Sudbury, Ontario Canada

E-mail: krebeiro@persona.ca

Ellie Fosey Department of Occupational Therapy School of Allied Health

La Trobe University Victoria 3086

Australia

E-mail: e.fossey@latrobe.edu.au

\section{References}

[1] L. Shaw and R. Lindsay, Renewing focus and building capacity for enacting authentic collaboration in work rehabilitation, Work: A Journal of Prevention, Assessment \& Rehabilitation 30 (2008), 215-218,

[2] G. Nelson, I. Prilleltensky and H. MacGillivary, Building value-based partnerships: toward solidarity with oppressed groups, American Journal of Community Psychology 29 (2001), 649-677,

[3] K. Rebeiro Gruhl, The employment rights of people with serious mental illness in Ontario: considering the influence of dominant ideology on marginalizing practices, WFOT Bulletin (2010), 33-39.

[4] T. Krupa and G. Carter, Enabling careers, autonomy, and prosperity: Using community organizing and building approaches to improve the educational outcomes of people with mental illness, Work: A Journal of Prevention, Assessment \& Rehabilitation (2012).
[5] B. Rinaudo and P. Ennals, Mental illness, supported education, employment and recovery: Ben's story, Work: A Journal of Prevention, Assessment \& Rehabilitation (2012).

[6] K. Cassinello and S. Bramley, Keeley's journey: from service user to service provider, Work: A Journal of Prevention, Assessment \& Rehabilitation (2012).

[7] K. Hatchard, J. Henderson and S. Stanton, Workers' perspectives on self-directing mainstream return to work following acute mental illness: reflections on partnerships, Work: A Journal of Prevention, Assessment \& Rehabilitation (2012).

[8] P. Villotti, M. Corbière, S. Zaniboni and F. Fraccaroli, Individual and environmental factors related to job satisfaction in people with severe mental illness employed in social enterprises, Work: A Journal of Prevention, Assessment \& Rehabilitation (2012).

[9] T. Paluch, E. Fossey and C. Harvey, Social firms: building cross-sectoral partnerships to create employment opportunity and supportive workplaces for people with mental illness. Work: A Journal of Prevention, Assessment \& Rehabilitation (2012).

[10] A. Williams, E. Fossey and C. Harvey, Social firms: sustainable employment for people with mental illness, Work: A Journal of Prevention, Assessment \& Rehabilitation (2012).

[11] K. Rebeiro Gruhl, Employment services for persons with serious mental illness in northern places: The case for partnerships, Work: A Journal of Prevention, Assessment \& Rehabilitation (2012).

[12] C. Fegan and S. Cook, Experiences of Volunteering - a partnership between service users and a mental health service in the UK. Work: A Journal of Prevention, Assessment \& Rehabilitation (2012).

[13] W. Bryant, J. Parsonage, A. Tibbs, C. Andrews, J. Clark and L. Franco, Meeting in the mist: key considerations in a collaborative research partnership with people with mental health issues, Work: A Journal of Prevention, Assessment \& Rehabilitation (2012)

[14] S. Moll, Navigating Political Minefields: Partnerships in Organizational Case Study Research, Work: A Journal of Prevention, Assessment \& Rehabilitation (2012).

[15] J. Dorio, Tying it all together - the pass to success: a comprehensive look at promoting job retention for workers with psychiatric disabilities in a supported employment program, Psychiatric Rehabilitation Journal 28(1) (2004), 32-39.

[16] E.S. Fabian, A. Waterworth and B. Ripke, Reasonable accommodations for workers with serious mental illness: Type, frequency, and associated outcomes, Psychosocial Rehabilitation Journal 17(2) (1993), 163-172.

[17] G.R. Bond, R.E. Drake and D.R. Becker, An update on randomised controlled trials of evidence-based supported employment, Psychiatric Rehabilitation Journal 31 (2008), 280290 , 